\title{
ANALISIS DAYA SAING BEBERAPA TANAMAN SAYURAN DI LAHAN SAWAH DI KECAMATAN PEUKAN BADA KABUPATEN ACEH BESAR
}

\section{(Analysys Of Competitiveness Of Some Vegetable Crops In Wetland In The}

Sub-District Of Peukan Bada Aceh Besar Regency)

\author{
Tiara Sucia ${ }^{1}$, Romano ${ }^{1}$, Irwan A Kadir ${ }^{1 *}$ \\ ${ }^{1}$ Program Studi Agribisnis, Fakultas Pertanian, Universitas Syiah Kuala
}

\begin{abstract}
Abstrak. Penelitian ini bertujuan untuk mengetahui jenis tanaman sayuran yang memiliki daya saing pada lahan sawah dan faktor-faktor pendukung sarana produksi yang diperlukan untuk meningkatkan produksi tanaman sayuran di lahan sawah. Metode Penelitian yang digunakan adalah metode survey sedangkan metode analisis adalah metode kualitatif deskriptif. Hasil penelitian ini menunjukkan bahwa bawang merah, cabai merah dan cabai rawit secara ekonomis memiliki daya saing. Namun, bawang merah belum memiliki daya saing pada tingkat produktivitas aktual dibandingkan usahatani cabai merah dan cabai rawit. Fakto-faktor pendukung sarana produksi usahatani bawang merah di Kecamatan Peukan Bada bukan hanya bibit unggul. Hasil perbandingan kondisi di lapangan penelitian dan Rekomendasi BPTP Aceh, pupuk dan teknik budidaya juga berpengaruh pada produksi usahatani bawang merah.
\end{abstract}

Kata Kunci : Daya Saing, Tanaman Sayuran, Pendapatan, Sarana Produksi

\begin{abstract}
This study aims to determine the type of vegetable crops that are competitive on the wetland and supporting factors of production facilities necessary to increase the production of vegetable crops in the wetland. The research method used is survey method while the method of analysis is descriptive qualitative method.The results of this study indicate that the onions, red peppers and chili sauce economically competitive. However, onion is not competitive on the level of actual productivity than farming red chili and cayenne pepper. Factors supporting production facilities onion farming in the sub-district of Peukan Bada not only of seeds. The results of the comparison conditions in the field of study and recommendation Food Crop Study Center of Aceh, fertilizer and cultivation techniques also affect the production of onion farming.
\end{abstract}

Keywords: Competitiveness, Vegetable Plants, Earnings, Production Facilities

\section{PENDAHULUAN}

Tanaman sayuran merupakan salah satu komoditi sayuran yang memiliki peluang untuk ditingkatkan produksinya di Kabupaten Aceh Besar. Aceh Besar merupakan salah satu kawasan yang masyarakatnya masih hidup dari sektor pertanian. Tanaman Sayuran juga merupakan salah satu tanaman yang penting 
bagi masyarakat, baik dari segi ekonomi maupun dari segi kandungan gizinya. Menurut Khoirunnisa et. al (2013) Sayuran merupakan komoditi yang memiliki harga cukup tinggi di pasaran. Tanaman sayuran dapat secara nyata mendatangkan keuntungan bagi petani, sehingga banyak petani yang membudidayakan tanaman sayuran. Dengan demikian, keberhasilan dalam usahatani sayuran dapat memberikan sumbangan yang besar bagi kesejahteraan petani.

Kecamatan Peukan Bada merupakan daerah yang subur untuk usaha pertanian, namun masyarakat tidak banyak yang fokus mengembangkan tanaman sayuran. Kebanyakan petani menanam padi sawah tadah hujan dan menjadi nelayan, hanya sebagian kecil yang membudidayakan tanaman sayuran. Daerah ini tidak memiliki komoditi unggulan yang dapat ditingkatkan produksinya. Komoditi sayuran hanya ditanam untuk menambah pendapatan keluarga sehingga produksi tiap tahunnya tidak stabil, artinya jika tahun 2007 petani menanam sayuran maka tahun selanjutnya petani tidak menanam tanaman sayuran jika bibit tidak tersedia atau harga bibit mahal. Komoditi yang mulai ditingkatkan produksinya dapat dilihat pada tabel 1,Kecamatan Peukan Bada Kabupaten Aceh Besar Tahun 2014.

Tabel 1. Luas Tanam, Luas Panen dan Produksi Sayuran di Kecamatan Peukan Bada Kabupaten Aceh Besar Tahun 2014.

\begin{tabular}{|r|l|r|r|r|r|}
\hline No & \multicolumn{1}{|c|}{ Komoditi } & \multicolumn{1}{c|}{$\begin{array}{c}\text { Luas Tanam } \\
\text { (Ha) }\end{array}$} & $\begin{array}{c}\text { Luas } \\
\text { Panen } \\
\text { (Ha) }\end{array}$ & \multicolumn{1}{c|}{$\begin{array}{c}\text { Produksi } \\
\text { (Ton) }\end{array}$} & \multicolumn{1}{c|}{$\begin{array}{c}\text { Produktivitas } \\
\text { (Ton/Ha) }\end{array}$} \\
\hline 1 & Bawang Merah & 10 & 7 & 71 & 10,1 \\
\hline 2 & Cabe Merah & 2 & 2 & 8 & 7 \\
\hline 3 & Cabe Rawit & 2 & 2 & 14 & 7,3 \\
\hline 4 & Kacang Panjang & 3 & 3 & 22 & 3,1 \\
\hline 5 & Kangkung & 10 & 9 & 28 & 1,5 \\
\hline 6 & Bayam & 19 & 18 & 28 & 12,5 \\
\hline 7 & Timun & 2 & 2 & 25 & 21 \\
\hline 8 & Semangka & 2 & 1 & 21 & 66,6 \\
\hline & Total & 50 & 44 & 217 & \\
\hline
\end{tabular}

Sumber: Badan Pusat Statistik Aceh (diolah), 2016

Berdasarkan Tabel 1 , terlihat bahwa secara keseluruhan total produksi sayuran sebanyak $217 \mathrm{~kg}$ per tahun dengan total produktivitas 66,6 ton/ha. Dari delapan sayuran yang dibudidayakan oleh petani, bawang merah memiliki produksi tertinggi diantara komoditi lainnya.

Penggunaan lahan menjadi hal yang sangat penting untuk meningkatkan produksi tanaman sayuran. Kebanyakan masyarakat menanam padi, biasanya ditanam hanya satu atau dua kali setahun yaitu pada musim tanam SeptemberJanuari dan Januari-Mei, dan sisanya akan dimanfaatkan untuk tanaman komoditi lainnya khususnya sayuran. Di lahan sawah, biasanya sayuran ditanam setelah padi dengan pola tanam padi-sayuran, hal ini potensial dilakukan untuk meningkatkan intensitas tanam dan meningkatkan produksi tanaman sayuran.

Analisis Daya Saing Beberapa Tanaman Sayuran Di Lahan Sawah Di Kecamatan Peukan Bada Kabupaten Aceh Besar (Tiara Sucia, Romano, Irwan A Kadir) 
Pemilihan komoditi sayuran yang akan dibudidaya oleh petani menjadi penentu dalam pemanfaatan lahan sawah. Hal ini dikarenakan tidak semua komditas tanaman sayuran cocok ditanam di lahan sawah. Faktor lainnya yang mempengaruhi penentuan komoditi yang ditanam adalah sumber daya yang dimiliki petani termasuk di dalamnya penyediaan bibit. menurut Krisdiana (2011) komoditi yang ditanam merupakan minat dari masing-masing petani sesuai keinginan dan kemampuan mereka. Pemilihan komoditi bergantung pada tujuan usahatani yang memaksimalkan keuntungan serta persepsi yang berbeda tentang resiko dan ketidakpastian yang terdapat pada masing-masing tanaman. Pada akhirnya keputusan memilih komoditi yang akan ditanam bergantung pada kondisi sumber daya yang dimiliki. Penelitian ini bertujuan untuk mengetahui jenis tanaman sayuran yang memiliki daya saing pada lahan sawah dan untuk mengetahui faktor-faktor pendukung sarana produksi yang diperlukan untuk meningkatkan produksi tanaman sayuran di lahan sawah.

\section{METODOLOGI PENELITIAN}

Penelitian ini dilakukan di Kecamatan Peukan Bada yang memiliki 14 desa. Penentuan lokasi penelitian dilakukan secara acak (simple random sampling), yaitu dengan mengambil desa secara acak di Kecamatan Peukan Bada. Dari 14 desa akan di ambil 3 desa dengan pertimbangan bahwa Desa Lam Mayang, Meunasah Tuha dan Lam Hasan merupakan desa yang banyak menanam tanaman sayuran di lahan sawah di Kecamatan Peukan Bada Kabupaten Aceh Besar. Objek penelitian ini adalah petani yang mengusahakan usahatani Bawang merah, cabai merah dan cabai rawit di lahan sawah di 3 desa. Ruang lingkup penelitian terbatas pada analisis daya saing beberapa tanaman sayuran (bawang merah, cabai merah dan cabai rawit) di lahan sawah, serta faktor-faktor pendukung sarana produksi yang diperlukan untuk meningkatkan produksi tanaman sayuran di lahan sawah.

Jenis data yang digunakan dalam penelitian ini adalah data primer yang diperoleh dari pengisian kuisioner dan wawancara langsung dengan para petani bawang merah, cabai merah dan cabai rawit. Data sekunder yang diperoleh dari berbagai referensi, seperti, buku bacaan, jurnal, dan skripsi yang berhubungan dengan penelitian ini.

Populasi dalam penelitian ini adalah petani yang berusahatani sayuran bawang merah, cabai merah dan cabai rawit di lahan sawah yang berada di Kecamatan Peukan Bada Kabupaten Aceh Besar. Teknik pengambilan sampel yang dilakukan adalah secara acak (simple random sampling), jumlah populasi dari 3 desa di Kecamatan Peukan Bada, jumlah populasi sebanyak 101 petani sayuran. Sampel yang diambil sebnayak $20 \%$ dari jumlah populasi petani per komoditi yang diusahakan di 3 desa. Maka jumlah sampel yang diteliti totalnya adalah 21 petani, 11 petani bawang merah, cabai merah dan cabai rawit di Desa Lam Mayang, 5 petani bawang merah, cabai merah dan cabai rawit di Desa Meunasah Tuha dan 5 petani bawang merah, cabai merah dan cabai rawit dari Desa Lam Hasan. Arikunto (2002) menjelaskan bahwa dalam penentuan sampel

Analisis Daya Saing Beberapa Tanaman Sayuran Di Lahan Sawah Di Kecamatan Peukan Bada Kabupaten Aceh Besar (Tiara Sucia, Romano, Irwan A Kadir) 
apabila jumlah sampelnya besar lebih dari 100 dapat diambil antara $10-15 \%$ atau 20-55\%. Besarnya sampel yang diambil dalam penelitian ini adalah $20 \%$ untuk petani dalam kelompok mengingat waktu, biaya dan kemampuan peneliti terbatas.

Metode analisis yang digunakan dalam penelitian ini adalah metode analisis kuantitatif dan metode deskriptif. Untuk menjawab hipotesa yang pertama digunakan analisis pendapatan, pendekatan $\mathrm{R} / \mathrm{C}$, titik impas produktivitas dan titik impas harga, dan menggunakan analisis keunggulan kompetitif.

a. Analisis Pendapatan digunakan formulasi (Soekartawi, 1996)

$$
\pi \quad=\mathrm{TR}-\mathrm{TC}
$$

\section{Keterangan :}

$\pi \quad=$ Profit/keuntungan $(\mathrm{Rp})$

$\mathrm{TR}=$ Total Revenue/total penerimaan usahatani $(\mathrm{Rp}$

$\mathrm{TC}=$ Total Cost/total biaya usahatani (Rp)

b. Analisis efisien usahatani digunakan pendekatan $\mathrm{R} / \mathrm{C}$ ratio yang rumusnya sebagai berikut (Hernanto, 1991) :

$\mathrm{R} / \mathrm{C}=\frac{\text { Total Penerimaan }}{\text { Pengeluaran }}$

Kriteria Pengambilan Keputusan :

1. $\mathrm{R} / \mathrm{C}>1$, maka usahatani menguntungkan

2. $\mathrm{R} / \mathrm{C} \leq 1$, maka usahatani tidak menguntungkan

3. Semakin tinggi nilai $\mathrm{R} / \mathrm{C}$ ratio, maka semakin tinggi daya saing komoditas

c. Untuk mengetahui titik impas produktivitas dan titik impas harga digunakan rumus sebagi berikut

1. Titik impas Produktivitas $(\mathrm{TIP})=\mathrm{Y}=\frac{\mathrm{BT}}{\mathrm{H}}$

2. Titik impas harga $(\mathrm{TIH})=\mathrm{H}=\frac{\mathrm{BT}}{\mathrm{Y}}$

Keterangan:
$\mathrm{H}=$ Harga
$\mathrm{Y}=$ Produktivitas
Komoditas
$(\mathrm{Rp} / \mathrm{Kg})$
$\mathrm{BT}=$ Biaya Total/Ha

Kriteria pengambilan keputusan :

Semakin rendah nilai BEP, semakin tinggi daya saing komoditas.

Analisis keunggulan kompetitif pada dasarnya analog dengan penentuan tingkat produktivitas minimal dari suatu komoditas, agar kompetitif terhadap usahatani komoditas lain. Kerangka analisis disajikan pada Tabel 2.

d. Untuk melakukan analisis keunggulan kompetitif digunakan tabel sebagai berikut (Ramli dan Dewa K.S Swastika, 2005) :

Analisis Daya Saing Beberapa Tanaman Sayuran Di Lahan Sawah Di Kecamatan Peukan Bada Kabupaten Aceh Besar (Tiara Sucia, Romano, Irwan A Kadir) 
Tabel 2. Kerangka Analisis Keunggulan Kompetitif

\begin{tabular}{|l|c|c|c|c|}
\hline Komoditas & $\begin{array}{c}\text { Produktivitas } \\
\text { (Ton/Ha) }\end{array}$ & $\begin{array}{c}\text { Harga } \\
(\mathrm{Rp} / \mathrm{Kg})\end{array}$ & $\begin{array}{c}\text { Biaya } \\
(\mathrm{Rp} / \mathrm{Ha})\end{array}$ & $\begin{array}{c}\text { Keuntungan } \\
(\mathrm{Rp} / \mathrm{Ha})\end{array}$ \\
\hline Komoditas A & Y1 & $\mathrm{H} 1$ & $\mathrm{D} 1$ & $\mathrm{E} 1$ \\
Komoditas B & $\mathrm{Y} 2$ & $\mathrm{H} 2$ & $\mathrm{D} 2$ & $\mathrm{E} 2$ \\
Komoditas C & Y3 & $\mathrm{H} 3$ & $\mathrm{D} 3$ & $\mathrm{E} 3$ \\
Keunggulan & & & & \\
Komoditas A: & & $\mathrm{P} 1$ & & \\
-terhadap B & $\mathrm{F} 1$ & $\mathrm{P} 2$ & & \\
-terhadap C & $\mathrm{F} 2$ & &
\end{tabular}

$$
\begin{array}{lll}
\text { Keterangan: } & \mathrm{F} 1=(\mathrm{E} 2+\mathrm{D} 1) / \mathrm{H} 1 & \mathrm{P} 1=(\mathrm{E} 2+\mathrm{D} 1) / \mathrm{Y} 1 \\
& \mathrm{~F} 2=(\mathrm{E} 3+\mathrm{D} 1) / \mathrm{H} 1 & \mathrm{P} 2=(\mathrm{E} 3+\mathrm{D} 1) / \mathrm{Y} 1
\end{array}
$$

Dimana :

F1 = Produktivitas minimum komoditas A agar kompetitif terhadap komoditas B

F2 = Produktivita minimum komoditas A agar kompetitif terhadap komoditas C

P1 = Harga minimum komoditas A agar kompetitif terhadap komoditas B

P2 = Harga minimum komoditas A agar kompetitif terhadap komoditas C

Untuk menjawab hipotesis kedua, yaitu mengetahui faktor-faktor pendukung yang diperlukan untuk meningkatkan produksi usahatani komoditas bawang merah akan dibahas dengan metode deskriptif, yaitu suatu metode yang meneliti status kelompok manusia, objek, kondisi, sistem pemikiran, dan peristiwa pada masa sekarang sesuai dengan kondisi saat observasi (Nazir, 2003).

\section{HASIL DAN PEMBAHASAN}

Karakteristik petani dalam penelitian terdiri dari umur, pendidikan, jumlah tanggungan, pengalaman dan jenis usahatani usahatani petani di tempat penelitian. (Lampiran 1) dari lampiran 1, Karakteristik petani di daerah penelitian dapat dilihat pada Tabel 3 .

Tabel 3. Rata-rata Karakteristik Petani Sayuran di Kecamatan Peukan Bada

\begin{tabular}{|c|c|c|c|c|c|c|}
\hline \multirow[b]{2}{*}{ No } & \multirow[b]{2}{*}{ Karakteristik } & \multirow[b]{2}{*}{ Satuan } & \multirow[b]{2}{*}{ Range } & \multicolumn{3}{|c|}{ Rata-Rata } \\
\hline & & & & $\begin{array}{l}\text { Cabai } \\
\text { Merah }\end{array}$ & $\begin{array}{l}\text { Cabai } \\
\text { Rawit }\end{array}$ & $\begin{array}{c}\text { Bawang } \\
\text { Merah }\end{array}$ \\
\hline 1 & Umur & Tahun & $30-68$ & 47 & 41 & 47 \\
\hline 2 & Pendidikan & Tahun & $6-15$ & 9 & 11 & 8 \\
\hline 3 & Tanggungan & Jiwa & $2-5$ & 3 & 5 & 4 \\
\hline 4 & Pengalaman & Tahun & $1-7$ & 3 & 3 & 3 \\
\hline & Total & & & 60 & 60 & 62 \\
\hline
\end{tabular}
Kabupaten Aceh Besar Tahun 2016.

Sumber : Data Primer(Diolah) 2016.

\section{Umur}

Analisis Daya Saing Beberapa Tanaman Sayuran Di Lahan Sawah Di Kecamatan Peukan Bada Kabupaten Aceh Besar (Tiara Sucia, Romano, Irwan A Kadir) 
Dari Tabel 3 dapat dilihat bahwa petani bawang merah berusia 47 tahun, cabai merah berusia 47 tahun dan cabai rawit 41 tahun, maka dapat disimpulkan bahwa petani di daerah ini termasuk dalam umur produktif.

Menurut undang-undang no 13 tahun 2003 Bab I pasal 1 tentang tenaga kerja, mereka yang dikelompokkan sebagai tenaga kerja produktif yaitu mereka yang berusia antara 15 tahun sampai 64 tahun. Putra et al (2006) menjelaskan bahwa umur merupakan salah satu aspek yang berhubungan dengan kemampuan fisik, psikologis dan biologis seseorang. Maka dapat disimpulkan bahwa sebagian besar responden tergolong usia muda dan produktif. Ini berarti petani bawang merah, cabai merah dan cabai rawit dapat melakukan pengembangan optimal dalam mengembangkan usahatani di Pekan Bada.

\section{Tingkat Pendidikan}

Pendidikan yang ditempuh oleh petani bawang merah, cabai merah dan cabai rawit memiliki perbedaan, diantaranya petani bawang merah dan cabai rawit menempuh pendidikan 8-9 tahun yaitu setara dengan SMP (Sekolah Menengah Pertama), sedangkan petani cabai merah menempuh pendidikan 11 tahun yaitu setara dengan SMA (Sekolah Menengah Atas). Maka dapat disimpulkan bahwa rata-rata petani tidak menempuh sekolah di perguruan tinggi, pendidikan tertinggi hanya menempuh sekolah menengah atas. Kebanyakan petani hanya mengandalkan pengalaman bertani, sehingga tidak banyak petani yang menggunakan inovasi dan teknologi dalam membudidaya usahataninya.

\section{Jumlah Tanggungan Keluarga}

Jumlah tanggungan keluarga petani sayuran di daerah penelitian rata-rata adalah untuk petani bawang merah 4 orang, rata-rata petani cabai rawit ada 3 orang dan rata-rata untuk petani cabai merah ada 5 orang. Jumlah tanggungan keluarga sangat mempengaruhi pendapatan dan pengeluaran petani. Adapun yang dimaksud dengan tanggungan keluarga secara umum dapat diartikan sebagai angka yang menunjukkan banyaknya penduduk pada usia tidak produktif ( 0-14 tahun dan > 65) yang harus ditanggung oleh keluarga.

\section{Pengalaman Usahatani}

Pengalaman petani dalam berusahatani di Peukan Bada adalah 3 tahun untuk petani bawang merah, 3 tahun untuk petani cabai merah dan 3 tahun untuk petani cabai rawit. Berdasarkan analisa tabel petani memiliki pengalaman 3 tahun dalam mengusahakan usahatani. Fakta dilapangan menunjukkan bahwa faktor pengalaman sangat mempengaruhi minat petani dalam memilih usahatani yang akan diusakannya. Setelah melakukan wawancara, petani tidak puas dengan usahatani cabai merah dan cabai rawit dikarenakan kegagalan panen yan sering dialami petani. Petani juga tidak suka menanam cabai dikarenakan faktor pemeliharaanya yang sulit dan mudahnya terserang hama penyakit.

Analisis Daya Saing Beberapa Tanaman Sayuran Di Lahan Sawah Di Kecamatan Peukan Bada Kabupaten Aceh Besar (Tiara Sucia, Romano, Irwan A Kadir)

Jurnal Ilmiah Mahasiswa Pertanian Unsyiah, Vol. 2, No. 3, Agustus 2017: 156-171 


\section{Analisis Daya Saing Usahatani Bawang Merah, Cabai Merah dan Cabai Rawit Di Kecamatan Peukan Bada Kabupaten Aceh Besar. \\ Keuntungan Usahatani}

Untuk melihat perbandingan usahatani sayuran yang unggul di Kecamatan Peukan Bada diukur berdasarkan analisis finansial dan analisis pendapatan. Analisis pendapatan menggunakan rumus $\pi=\mathrm{TR}-\mathrm{TC}$ dimana keuntungan sama dengan total penerimaan usahatani dikurang total biaya produksi usahatani. Sehingga dapat dilihat pada tabel 4 bahwa keuntungan usahatani bawang Merah, cabai merah dan cabai rawit di lahan sawah dikonversikan ke dalam 1 hektar.

Tabel 4. Keuntungan Usahatani Bawang Merah, Cabai Merah dan Cabai Rawit di Lahan Sawah Dikonversikan Ke Dalam 1 Hektar.

\begin{tabular}{|l|c|c|c|c|c|c|}
\hline Usahatani & $\begin{array}{c}\text { Luas } \\
\text { Lahan } \\
(\mathbf{H a})\end{array}$ & $\begin{array}{c}\text { Produksi } \\
(\mathbf{k g})\end{array}$ & $\begin{array}{c}\text { Harga } \\
(\mathbf{R p / K u})\end{array}$ & $\begin{array}{c}\text { Penerimaan } \\
(\mathbf{R p})\end{array}$ & $\begin{array}{c}\text { Biaya } \\
\text { Produksi } \\
(\mathbf{R p})\end{array}$ & $\begin{array}{c}\text { Keuntungan } \\
(\mathbf{R p})\end{array}$ \\
\hline $\begin{array}{l}\text { Bawang } \\
\text { Merah }\end{array}$ & 1 & $2.752,73$ & 35.000 & 96.363 .636 & 11.247 .164 & 85.116 .473 \\
\hline $\begin{array}{l}\text { Cabai } \\
\text { Merah }\end{array}$ & 1 & 2.675 & 40.000 & 202.380 .917 & 44.575 .417 & 157.805 .500 \\
\hline $\begin{array}{l}\text { Cabai } \\
\text { Rawit }\end{array}$ & 1 & $7.307,69$ & 30.000 & 219.230 .769 & 49.970 .692 & 169.260 .077 \\
\hline
\end{tabular}

Sumber : Analisis data peimer Penelitian(diolah ),2016.

Dari Tabel 4 dapat dilihat bahwa, jika lahan usahatani dikonversikan dalam 1 hektar berdasarkan data dilapangan maka cabai rawit memiliki keuntungan lebih tinggi Rp.169.260.077 dengan hasil produksi 7.307,69 kg dibandingkan dengan usahatani bawang merah dan cabai merah, sedangkan keuntungan yang paling rendah adalah bawang merah $\mathrm{Rp}$. 85.116.473 dengan hasil produksi $2.752,73 \mathrm{Kg}$.

Dari analisis dabel diatas menunjukkan bahwa usahatani cabai rawit akan menghasilkan keuntungan 4 kali lipat dari biaya produksi jika luas lahan yang digunakan adalah 1 hektar. Syukur (2016) menjelaskan bahwa tingginya produksi cabai dipengaruhi oleh luasan panen dan produktivitas lahan. Selain itu faktor iklim juga sangat mempengaruhi produksi cabai.

\section{Analisis Finansial}

\section{Analisis Efisiensi Usahatani}

Untuk mengetahui apakah usahatani sayuran yang dilakukan petani dikatakan efesien maka perlu dilakukan analisis menggunakan $\mathrm{R} / \mathrm{C}$ ratio. Dimana $\mathrm{R} / \mathrm{C}$ adalah perbandingan antara total penerimaan dengan biaya-biaya produksi. $\mathrm{R} / \mathrm{C}$ digunakan untuk mengukur tingkat efesiensi biaya dari suatu usahatani. Usahatani dikatakan efesien apabila nilai $\mathrm{R} / \mathrm{C}>1$, dan dikatakan tidak efesien jika nilai $\mathrm{R} / \mathrm{C} \leq 1$. Nilai $\mathrm{R} / \mathrm{C}$ ini dapat dilihat pada Tabel 5 .

Analisis Daya Saing Beberapa Tanaman Sayuran Di Lahan Sawah Di Kecamatan Peukan Bada Kabupaten Aceh Besar (Tiara Sucia, Romano, Irwan A Kadir) 
Tabel 5. Analisi Finansial Usahatani Bawang Merah, Cabai Merah dan Cabai rawit di Kecamatan Peukan Bada.

\begin{tabular}{|l|c|c|c|c|}
\hline \multicolumn{1}{|c|}{ Usahatani } & $\begin{array}{c}\text { Penerimaan } \\
(\mathbf{R p})\end{array}$ & $\begin{array}{c}\text { Biaya Produksi } \\
(\mathbf{R p})\end{array}$ & $\begin{array}{c}\text { Keuntungan } \\
(\mathbf{R p})\end{array}$ & $\begin{array}{c}\text { Nilai } \\
\text { R/C }\end{array}$ \\
\hline Bawang Merah & 96.363 .636 & 11.247 .164 & 85.116 .473 & 8,5 \\
\hline Cabai Merah & 202.380 .917 & 44.575 .417 & 157.805 .500 & 4,5 \\
\hline Cabai Rawit & 219.230 .769 & 49.970 .692 & 169.260 .077 & 4,3 \\
\hline
\end{tabular}

Sumber : Analisis data peimer Penelitian (diolah), 2016

Tabel 5 menunjukkan nilai $\mathrm{R} / \mathrm{C}$ masing-masing usahatani tanaman sayuran lebih besar dari 1, dengan nilai usahatani bawang merah sebesar 8,5 pada usahatani cabai merah sebesar 4,5 dan usahatani cabai rawit sebesar 4,3. Ini menunjukkan bahwa penggunaan biaya produksi pada usahatani bawang merah, cabai merah dan cabai rawit secara ekonomis efissien dan menguntungkan. Namun pada kondisi dilapangan, bawang merah memiliki daya saing dan keuntungan lebih tinggi sebesar 8,5 dibandingkan dengan cabai merah dan cabai rawit.

\section{Analisis Titik Impas Produktivitas (TIP) dan Titik Impas Harga (TIH) Titik Impas Produktivitas}

Titik impas produksi menyatakan produksi minimal di mana usahatani dapat memberikan keuntungan normal. Hasil analisis titik impas produksi masingmasing usahatani bawang merah, cabai merah dan cabai rawit dapat dilihat pada tabel 6.

Tabel 6. Titik Impas Produksi Usahatani Bawang Merah, Cabai Merah dan Cabai Rawit Per Musim Tanam.

\begin{tabular}{|l|c|c|c|c|c|}
\hline \multicolumn{1}{|c|}{ Usahatani } & $\begin{array}{c}\text { Luas } \\
\text { Lahan } \\
(\mathbf{H a})\end{array}$ & $\begin{array}{c}\text { Biaya } \\
\text { Produksi } \\
(\mathbf{R p})\end{array}$ & $\begin{array}{c}\text { Harga } \\
\text { Usahatani } \\
(\mathbf{R p} / \mathbf{K g})\end{array}$ & $\begin{array}{c}\text { Titik Impas } \\
\text { Produksi } \\
(\mathbf{K g})\end{array}$ & $\begin{array}{c}\text { Hasil } \\
\text { Produksi } \\
(\mathbf{K g})\end{array}$ \\
\hline Bawang Merah & 1 & 11.247 .164 & 35.000 & 321,3 & $2.752,7$ \\
\hline Cabai Merah & 1 & 44.575 .417 & 40.000 & 1114,3 & 2.675 \\
\hline Cabai Rawit & 1 & 49.970 .692 & 30.000 & 1665,6 & $7.307,6$ \\
\hline
\end{tabular}

Sumber : Analisis data peimer Penelitian (diolah) 2016

Tabel 6 menunjukkan bahwa lahan yang dikonversikan ke dalam 1 hektar maka titik impas produksi bawang merah sebesar $321,3 \mathrm{~kg}$ lebih rendah dibandingkan produksi aktual sebesar $2.752,7 \mathrm{~kg}$. Begitu juga dengan titik impas produksi cabai merah $1114,3 \mathrm{~kg}$ dan cabai rawit $1665,6 \mathrm{~kg}$ lebih rendah dibandingkan dengan hasil produksi aktual di lokasi penelitian sebesar $2.675 \mathrm{~kg}$ cabai merah dan 7.307,6 kg cabai rawit. Maka dapat disimpulkan bahwa petani tidak mengalami kerugian pada produksi aktual. Namun jika petani memperoleh hasil produksi di bawah titik impas produksi maka petani mengalami kerugian dan jika di atas titik impas maka petani memiliki keuntungan.

Analisis Daya Saing Beberapa Tanaman Sayuran Di Lahan Sawah Di Kecamatan Peukan Bada Kabupaten Aceh Besar (Tiara Sucia, Romano, Irwan A Kadir) 


\section{Titik Impas Harga}

Titik impas harga merupakan batas minimal harga jual yang boleh dibebankan pada barang hasil produksi agar usahatani yang dijalankan tidak mengalami kerugian. Untuk mengetahui harga minimal yang dapat dibebankan pada penjual hasil produksi bawang merah, cabai merah dan cabai rawit petani perlu mengetahui titik impas harga dengan cara membandingkan antara total biaya produksi dengan hasil produksi yang diperoleh saat panen (Maspur dan Shophal, 2008). Berikut titik impas harga produksi usahatani bawang merah, cabai merah dan cabai rawit yang dapat dilihat pada tabel 7 .

Tabel 7. Titik Impas Harga Usahatani Bawang Merah, Cabai Merah dan Cabai Rawit Per Musim Tanam.

\begin{tabular}{|c|c|c|c|c|c|}
\hline Usahatani & $\begin{array}{c}\text { Luas } \\
\text { Lahan } \\
(\mathbf{H a})\end{array}$ & $\begin{array}{c}\text { Biaya } \\
\text { Produksi } \\
(\mathbf{R p})\end{array}$ & $\begin{array}{c}\text { Hasil } \\
\text { Produksi } \\
(\mathbf{K g})\end{array}$ & $\begin{array}{c}\text { Titik Impas } \\
\text { Harga } \\
(\mathbf{R p / K g})\end{array}$ & $\begin{array}{c}\text { Harga } \\
\text { Pasar } \\
(\mathbf{R p} / \mathbf{K g})\end{array}$ \\
\hline Bawang Merah & 1 & 11.247 .164 & $2.752,7$ & 4.085 & 35.000 \\
\hline Cabai Merah & 1 & 44.575 .417 & 2.675 & 16.664 & 40.000 \\
\hline Cabai Rawit & 1 & 49.970 .692 & $7.307,6$ & 6.838 & 30.000 \\
\hline
\end{tabular}

Sumber : Analisis data peimer Penelitian (diolah), 2016

Pada tabel 7 hasil analisi menunjukkan bahwa titik impas harga bawang merah sebesar Rp 4.085/kg, cabai merah sebesar Rp 16.664/kg dan cabai rawit Rp $6.838 / \mathrm{kg}$ lebih rendah dari harga aktual dimana harga bawang merah Rp $35.000 / \mathrm{kg}$, cabai merah Rp40.000/kg dan cabai rawit 30.000/kg . Maka dapat disimpulkan bahwa petani bawang merah, cabai merah dan cabai rawit tidak mengalami kerugian karena harga aktual lebih tinggi dibandingkan titik impas harga.

Tinggi rendahnya nilai titik impas harga ini tergantung pada banyaknya hasil produksi yang diperoleh. Semakin tinggi jumlah hasil produksi, maka nilai titik impas harga akan semakin kecil. Menurut Baharsyah (1995) salah satu alasan produsen atau petani dalam meningkatkan hasil pertaniannya mereka adalah harga, sebab dengan bersaing dan tingginya harga maka pendapatan yang diterima petani akan meningkat pula.

\section{Keunggulan Kompetitif Bawang Merah, Cabai Merah dan Cabai Rawit}

Tingkat keunggulan kompetitif usahatani terhadap usahatani lain dapat diketahui melalui analisis tingkat harga dan produktivitas yang relatif tidak berubah. Dari analisis ini akan diketahui tingkat hasil minimal dari suatu usahatani agar dapat kompetitif dengan usahatani usahatani lainnya ( Ramli dan Dewa, 2005).

Berdasarkan studi lapangan, bahwa usahatani yang dominan adalah bawang merah. Oleh karena itu, dalam pengkajian ini usahatani bawang merah merupakan basis analisis dan evaluasi tingkat daya saing terhadap cabai merah dan cabai rawit. Berikut disajikan tabel 8. kerangka analisis keunggulan

Analisis Daya Saing Beberapa Tanaman Sayuran Di Lahan Sawah Di Kecamatan Peukan Bada Kabupaten Aceh Besar (Tiara Sucia, Romano, Irwan A Kadir) 
kompetitif usahatani bawang merah terhadap cabai merah dan cabai rawit berdasarkan data luas lahan di lapangan per musim tanam.

Tabel 8. Kerangka Analisis Keunggulan Kompetitif Usahatani Bawang Merah Terhadap Cabai Merah dan Cabai Rawit Per Produksi Pada Luas Lahan 1 Hektar Per Musim Tanam.

\begin{tabular}{|c|c|c|c|c|}
\hline Usahatani & $\begin{array}{l}\text { Produktivitas } \\
(\mathrm{Kg} / \mathrm{Ha})\end{array}$ & $\begin{array}{c}\text { Harga } \\
(\mathbf{R p} / \mathbf{K g})\end{array}$ & $\begin{array}{c}\text { Biaya } \\
\text { Produksi } \\
\text { ( Rp/Kg) }\end{array}$ & $\begin{array}{c}\text { Keuntungan } \\
\text { (Rp/Kg) }\end{array}$ \\
\hline Bawang Merah & $2.752,73$ & 35.000 & 11.247 .164 & 85.116 .473 \\
\hline Cabai Merah & 2.675 & 40.000 & 44.575 .417 & 157.805 .500 \\
\hline Cabai Rawit & $7.307,69$ & 30.000 & 49.970 .692 & 169.260 .077 \\
\hline \multicolumn{5}{|c|}{ Keunggulan Usahatani Bawang Merah } \\
\hline $\begin{array}{c}\text { - Terhadap Cabai } \\
\text { merah }\end{array}$ & 4830,07 & 61.413 & & \\
\hline $\begin{array}{c}\text { - Terhadap Cabai } \\
\text { Rawit }\end{array}$ & 5157,34 & 65.574 & & \\
\hline
\end{tabular}

Sumber : Analisis data peimer Penelitian (diolah), 2016.

Berdasarkan hasil analisis tingkat keunggulan kompetitif pada Tabel 8 dari usahatani bawang merah di Kecamatan Peukan Bada agar dapat bersaing dengan cabai merah dan cabai kecil memerlukan produksi masing-masing sebesar $4830,07 \mathrm{~kg} / \mathrm{ha}$ terhadap cabai merah dan $5157,34 \mathrm{~kg} / \mathrm{ha}$ terhadap cabai rawit, yaitu diatas produksi aktual. Sedangkan harga minimal yang harus dicapai oleh bawang merah adalah Rp. 61.413 (terhadap cabai merah) dan Rp. 65.574 (terhadap cabai rawit). Kedua tingkat harga minimal yang harus dicapai ternyata diatas harga aktual, sehingga bawang merah belum kompetitif terhadap cabai merah dan cabai rawit dari harga dan juga dari produksi.

\section{Faktor-Faktor Pendukung Sarana Produksi Yang Diperlukan Untuk Meningkatkan Produksi Usahatani Bawang Merah, Cabai Merah dan Cabai Rawit. \\ Komponen Teknologi Pada Bawang Merah}

Adanya Perbedaan komponen teknologi pada usahatani bawang merah setelah melakukan perbandingan antara hasil penelitian di lapangan dan Balai Pengkaji Teknologi Pertanian Aceh (BPTP) Aceh. Ternyata bukan hanya bibit unggul yang mempengaruhi produktivitas bawang merah di lapangan, tetapi penggunaan pupuk yang masih kurang tepat dan teknis yang kurang sistematis menjadi salah satu faktor yang harus diperhatikan oleh petani . Perbandingani komponen teknologi pada usahatani bawang merah saat penelitian dan rekomendasi dari BPTP Aceh disajikan pada Tabel 9.

Analisis Daya Saing Beberapa Tanaman Sayuran Di Lahan Sawah Di Kecamatan Peukan Bada Kabupaten Aceh Besar (Tiara Sucia, Romano, Irwan A Kadir) 
Tabel 9. Perbandingan Komponen Teknologi Pada Usahatani Bawang Merah Saat Penelitian Di Kecamatan Peukan Bada Dan Hasil Rekomendari Dari Balai Pengkaji Teknologi Pertanian Aceh (BPTP Aceh ).

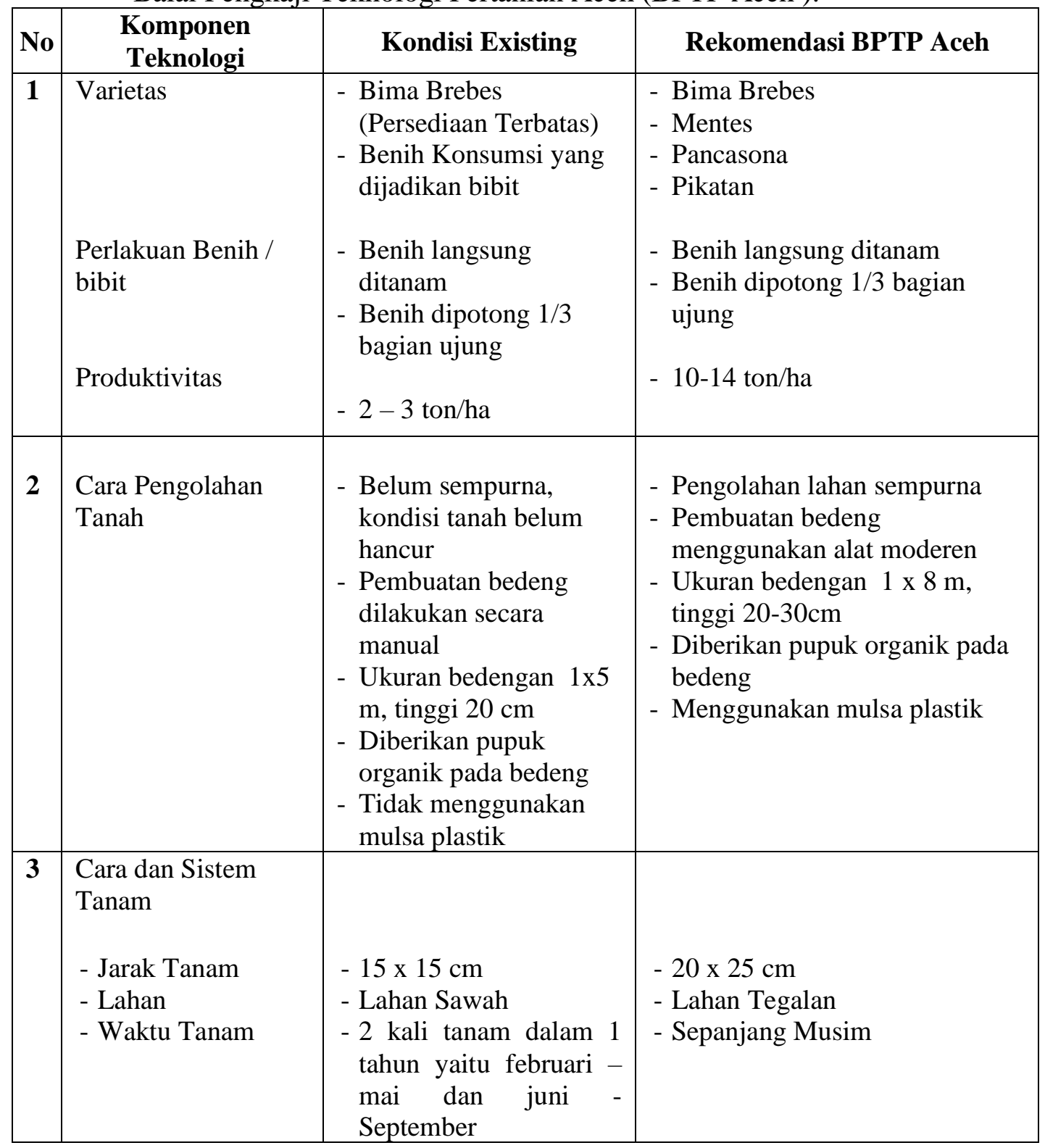

Analisis Daya Saing Beberapa Tanaman Sayuran Di Lahan Sawah Di Kecamatan Peukan Bada Kabupaten Aceh Besar (Tiara Sucia, Romano, Irwan A Kadir) 


\begin{tabular}{|c|c|c|c|}
\hline No & $\begin{array}{c}\text { Komponen } \\
\text { Teknologi }\end{array}$ & Kondisi Existing & Rekomendasi BPTP Aceh \\
\hline 4 & $\begin{array}{l}\text { Pemupukan } \\
\text { - Jenis } \\
\text { - Dosis } \\
\text { - Cara } \\
\text { - Waktu }\end{array}$ & $\begin{array}{l}\text { - Pupuk kandang, Urea, } \\
\text { SP 36, KCL } \\
\text { - Tidak ada takaran } \\
\text { tertentu } \\
\text { - Di tabur di bedengan } \\
\text { Pemakaian pupuk dasar } \\
\text { dilakukan pada bedengan } \\
\text { menggunakan pupuk } \\
\text { kandang }\end{array}$ & $\begin{array}{l}\text { - Urea, TSP, NPK, KCL, ZA dan } \\
\text { Pupuk Organik } \\
\text { - Ditabur dibedengan dan di cor } \\
\text { Pemakaian pupuk dasar non } \\
\text { organik dan organik dilakukan } \\
\text { pada bedengan sebelum tanam, } \\
\text { pemupukan susulan dengan } \\
\text { Pengecoran pada umur } 10 \text {-30 } \\
\text { hari. }\end{array}$ \\
\hline 5 & $\begin{array}{l}\text { Pemeliharaan } \\
\text { - Penyiangan } \\
\text { - Pengendalian OPT }\end{array}$ & $\begin{array}{l}\text { Dilakukan penyiangan, } \\
\text { tapi tidak sempurna. } \\
\text { Pengendalian OPT } \\
\text { dilakukan dengan } \\
\text { interrval dan dosis } \\
\text { pemberian tidak jelas, } \\
\text { dilakukan dengan } \\
\text { penyemprotan }\end{array}$ & $\begin{array}{l}\text { Dilakukan penyiangan dengan } \\
\text { sempurna } \\
\text { Pengendalian OPT delakukan } \\
\text { dengan metode PHT }\end{array}$ \\
\hline
\end{tabular}

Sumber : Analisis data peimer Penelitian (diolah), 2016.

Dari Tabel 9 dapat dilihat bahwa kondisi sebagian petani bawang merah di Kecamatan Peukan Bada masih menggunakan bibit konsumsi. Penggunaan bibit unggul masih kurang optimal pada pengolahan tanah, pemberian pupuk dan pengendalian OPT. Kondisi ini jauh berbeda dari Rekomendasi BPTP yang mengolahan lahan dengan sempurna, pemberian pupuk yang tepat dosis dan pengendalian OPT dengan metode PHT.

\section{Komponen Teknologi Pada Cabai Merah}

Benih unggul yang digunakan petani adalah varietas cabai keriting hibrida lado F1. Pada luasan lahan 0,026 ha petani memproduksi cabai merah sebesar 64,2 kg, jika dikonversikan pada luasan lahan 1 ha maka produksi cabai merah sebesar $2.675 \mathrm{~kg}$. Kondisi ini sangat jauh dari produksi seharusnya yang bisa menghasilkan 20 ton/ha. Syukur (2016) menjelaskan bahwa varietas ini sering disebut keriting hibrida all season ( semua musim ) karena memiliki kecocokan untuk ditanam pada segala musim serta di berbagai ketinggian yang berbeda. Produktivitasnya dapat dapat mencapai $1,2 \mathrm{~kg}$ per tanaman dengan potensi hasil sekitar 20 ton/ha. Berikut disajikan rekomendasi pemupukan dari Balai Pengkaji Teknologi Pertanian Aceh dapat dilihat pada tabel 10.

Analisis Daya Saing Beberapa Tanaman Sayuran Di Lahan Sawah Di Kecamatan Peukan Bada Kabupaten Aceh Besar (Tiara Sucia, Romano, Irwan A Kadir)

Jurnal Ilmiah Mahasiswa Pertanian Unsyiah, Vol. 2, No. 3, Agustus 2017: 156-171 
Tabel 10. Perbandingan Komponen Teknologi Pada Usahatani Cabai Merah Saat Penelitian Di Kecamatan Peukan Bada Dan Hasil Rekomendari Dari Balai Pengkaji Teknologi Pertanian Aceh (BPTP Aceh ).

\begin{tabular}{|c|c|c|c|}
\hline \multicolumn{2}{|c|}{ No Komponen Teknologi } & Kondisi Existing & Rekomendasi BPTP Aceh \\
\hline 1 & $\begin{array}{l}\text { Varietas } \\
\text { Produktivitas }\end{array}$ & $\begin{array}{l}\text { - keriting hibrida lado F1 } \\
\text { - 2,7 ton }\end{array}$ & $\begin{array}{l}\text { - Lokal Odeng } \\
\text { - } 20 \text { ton }\end{array}$ \\
\hline 2 & $\begin{array}{l}\text { Cara Pengolahan } \\
\text { Tanah }\end{array}$ & $\begin{array}{l}\text { - Belum sempurna, } \\
\text { pengolahan lahan } \\
\text { dilakukan 1minggu } \\
\text { sebelum tanam } \\
\text { - Pembuatan bedeng } \\
\text { dilakukan secara } \\
\text { tradisional ( manual) } \\
\text { - Ukuran bedengan } 1 \mathrm{x} \\
\text { 6m, tinggi } 20 \mathrm{~cm} \text { jarak } \\
\text { antar bedeng } 1 \mathrm{~m} \\
\text { - Diberikan pupuk organik } \\
\text { pada bedeng } \\
\text { - Tidak menggunakan } \\
\text { mulsa plastik } \\
\text { - Tidak ada ajir }\end{array}$ & $\begin{array}{l}\text { - Pengolahan lahan } 1 \text { bulan } \\
\text { sebelum tanam } \\
\text { - Pembuatan bedeng } \\
\text { menggunakan alat moderen } \\
\text { - Ukuran bedengan } 1,5 \mathrm{~m} \times 5 \mathrm{~m} \\
\text {, tinggi } 30 \mathrm{~cm} \text {, jarak antar } \\
\text { bedeng } 0,5 \mathrm{~m} \\
\text { - Pupuk dasar, urea, SP } 36 \text { dan } \\
\mathrm{KCl} \text { dosisnya 200, } 150 \text { dan } \\
150 \mathrm{~kg} / \mathrm{ha} \text { ( } 1 \text { minggu } \\
\text { sebelum tanam) } \\
\text { - Menggunakan mulsa plastik ( } \\
\text { MPHP) } \\
\text { - Dibuat ajir }\end{array}$ \\
\hline 3 & $\begin{array}{l}\text { Cara dan Sistem } \\
\text { Tanam } \\
\text { - Jarak Tanam } \\
\text { - Jenis Lahan } \\
\text { - Waktu Tanam }\end{array}$ & $\begin{array}{l}-50 \mathrm{~cm} \times 50 \mathrm{~cm} \\
\text { - Lahan Sawah } \\
\text { - } 2 \text { kali tanam dalam } 1 \\
\text { tahun yaitu februari - } \\
\text { mai dan juni - September }\end{array}$ & $\begin{array}{l}-50 \mathrm{~cm} \text { x } 50 \mathrm{~cm} \\
\text { - Lahan Tegalan } \\
\text { - Sepanjang Musim }\end{array}$ \\
\hline 4 & $\begin{array}{l}\text { Pemupukan Dasar } \\
\text { - Pupuk Organik } \\
\text { - NPK Mutiara } \\
\text { - Dolomit } \\
\text { - Pemupukan } \\
\text { Susulan }\end{array}$ & $\begin{array}{c}6 \mathrm{~kg} / 0,025 \mathrm{ha} \\
- \\
- \\
8 \mathrm{~kg} / \mathrm{ha} \text { Urea }+\mathrm{SP} 3621 \\
\mathrm{~kg} / \mathrm{ha} \text { dan } 4,5 \mathrm{~kg} / \mathrm{ha} \mathrm{KCL} \\
\text { Diberikan tidak beraturan }\end{array}$ & $\begin{array}{l}1,5 \mathrm{ton} / 0,25 \text { ha } \\
25 \mathrm{~kg} / 0,25 \mathrm{ha} \\
150 \mathrm{~kg} / 0,25 \mathrm{ha} \\
\\
70 \mathrm{~kg} / \mathrm{ha} \mathrm{NPK}+45 \mathrm{~kg} / \mathrm{ha} \mathrm{ZA} \\
\text { (dicor), yang diberikan pada } \\
\text { saat tanaman sebanyak } 8 \text { kali } \\
\text { dengan interval waktu } 10 \text { hari. }\end{array}$ \\
\hline 5 & Pemeliharaan & & \\
\hline
\end{tabular}

Analisis Daya Saing Beberapa Tanaman Sayuran Di Lahan Sawah Di Kecamatan Peukan Bada Kabupaten Aceh Besar (Tiara Sucia, Romano, Irwan A Kadir) Jurnal Ilmiah Mahasiswa Pertanian Unsyiah, Vol. 2, No. 3, Agustus 2017: 156-171 


\begin{tabular}{|l|l|l|l|}
\hline No & Komponen Teknologi & \multicolumn{1}{|c|}{ Kondisi Existing } & \multicolumn{1}{|c|}{ Rekomendasi BPTP Aceh } \\
\hline \multirow{3}{*}{ - Penyiangan } & $\begin{array}{l}\text { Dilakukan penyiangan, tapi } \\
\text { tidak sempurna. }\end{array}$ & $\begin{array}{l}\text { Dilakukan penyiangan dengan } \\
\text { sempurna }\end{array}$ \\
- Pengendalian OPT & $\begin{array}{l}\text { Pengendalian OPT } \\
\text { dilakukan dengan interrval } \\
\text { dan dosis pemberian tidak } \\
\text { jelas, dilakukan dengan } \\
\text { penyemprotan }\end{array}$ & $\begin{array}{l}\text { Pengendalian OPT delakukan } \\
\text { dengan metode PHT }\end{array}$ \\
\hline
\end{tabular}

Dari Tabel 10 dapat disimpulkan bahwa petani cabai merah belum melakukan pengolahan lahan dengan sempurna. Penggunaan pupuk yang tidak tepat dosis dan diberikan tidak beraturan. Dan penanganan OPT yang belum optimal.

\section{Komponen Teknologi Pada Cabai Rawit}

Petani pekan bada menggunakan benih sendiri. kondisi dilapangan usahatani cabai rawit juga sama halnya dengan usahatani cabai merah yang banyak terserang hama dan penyakit. Hasil pengamatan di lapangan banyak petani yang tidak melakukan teknik budidaya yang tepat sehingga berdampak pada produktivitas. berikut disajikan Tabel 11 perbandingan komponen teknologi pada usahatani cabai rawit saat penelitian di Kecamatan Peukan Bada.

Tabel 11. Perbandingan Komponen Teknologi Pada Usahatani Cabai Rawit Saat Penelitian Di Kecamatan Peukan Bada Dan Hasil Rekomendari Dari Balai Pengkaji Teknologi Pertanian Aceh (BPTP Aceh ).

\begin{tabular}{|c|c|c|c|}
\hline No & $\begin{array}{c}\text { Komponen } \\
\text { Teknologi }\end{array}$ & Kondisi Existing & BPTP Aceh \\
\hline 1 & $\begin{array}{l}\text { Varietas } \\
\text { Produktivitas }\end{array}$ & $\begin{array}{l}\text { - Benih Konsumsi yang } \\
\text { dijadikan benih usahtani } \\
\text { cabai rawit } \\
\text { - } 7,3 \text { ton }\end{array}$ & $\begin{array}{l}\text { - Bibit Unggul } \\
\text { - } 20 \text { ton }\end{array}$ \\
\hline 2 & $\begin{array}{l}\text { Cara Pengolahan } \\
\text { Tanah }\end{array}$ & $\begin{array}{l}\text { - Belum sempurna, } \\
\text { pengolahan lahan } \\
\text { dilakukan } 1 \text { minggu } \\
\text { sebelum tanam } \\
\text { - Pembuatan bedeng } \\
\text { dilakukan secara } \\
\text { tradisional ( manual) } \\
\text { - Ukuran bedengan } 1 \text { x } 6 \mathrm{~m} \text {, } \\
\text { tinggi } 20 \mathrm{~cm} \text { jarak antar } \\
\text { bedeng } 1 \mathrm{~m} \\
\text { - Diberikan pupuk kandang } \\
\text { pada bedeng }\end{array}$ & $\begin{array}{l}\text { - Pengolahan lahan } 1 \text { bulan } \\
\text { sebelum tanam } \\
\text { - Pembuatan bedeng } \\
\text { menggunakan alat moderen } \\
\text { - Ukuran bedengan } 1 \mathrm{~m} \times 5 \mathrm{~m} \\
\text {, tinggi } 30 \mathrm{~cm} \text {, jarak antar } \\
\text { bedeng } 0,5 \mathrm{~m} \\
\text { - Pupuk dasar, urea, SP } 36 \\
\text { dan KCl dosisnya } 200,150 \\
\text { dan } 150 \mathrm{~kg} / \mathrm{ha} \mathrm{(} 1 \text { minggu } \\
\text { sebelum tanam) } \\
\text { - Menggunakan mulsa }\end{array}$ \\
\hline
\end{tabular}

Analisis Daya Saing Beberapa Tanaman Sayuran Di Lahan Sawah Di Kecamatan Peukan Bada Kabupaten Aceh Besar (Tiara Sucia, Romano, Irwan A Kadir) Jurnal Ilmiah Mahasiswa Pertanian Unsyiah, Vol. 2, No. 3, Agustus 2017: 156-171 


\begin{tabular}{|c|c|c|c|}
\hline No & $\begin{array}{l}\text { Komponen } \\
\text { Teknologi }\end{array}$ & Kondisi Existing & BPTP Aceh \\
\hline & & $\begin{array}{l}\text { - Tidak menggunakan mulsa } \\
\text { plastik } \\
\text { - Tidak ada ajir }\end{array}$ & $\begin{array}{l}\text { plastik ( MPHP) } \\
\text { - Dibuat ajir }\end{array}$ \\
\hline 3 & $\begin{array}{l}\text { Cara dan Sistem } \\
\text { Tanam } \\
\text { - Jarak Tanam } \\
\text { - Pola Tanam } \\
\text { - Waktu Tanam }\end{array}$ & $\begin{array}{l}-50 \mathrm{~cm} \text { x } 50 \mathrm{~cm} \\
\text { - Lahan Sawah } \\
\text { - } 2 \text { kali tanam dalam } 1 \text { tahun } \\
\text { yaitu februari - mai dan } \\
\text { juni - September }\end{array}$ & $\begin{array}{l}-50 \mathrm{~cm} \text { x } 50 \mathrm{~cm} \\
\text { - Lahan Tegalan } \\
\text { - Sepanjang Musim }\end{array}$ \\
\hline 4 & $\begin{array}{l}\text { Pemupukan Dasar } \\
\text { - Pupuk Organik } \\
\text { - NPK Mutiara } \\
\text { - Dolomit } \\
\text { - Pemupukan } \\
\text { Susulan }\end{array}$ & $\begin{array}{c}6 \mathrm{~kg} / 0,025 \mathrm{ha} \\
- \\
- \\
8 \mathrm{~kg} / \mathrm{ha} \text { Urea }+\mathrm{SP} 3621 \\
\mathrm{~kg} / \mathrm{ha} \text { dan } 4,5 \mathrm{~kg} / \mathrm{ha} \mathrm{KCL} \\
\text { Diberikan tidak beraturan }\end{array}$ & $\begin{array}{l}1,5 \text { ton } / 0,25 \text { ha } \\
25 \mathrm{~kg} / 0,25 \mathrm{ha} \\
150 \mathrm{~kg} / 0,25 \mathrm{ha} \\
70 \mathrm{~kg} / \mathrm{ha} \mathrm{NPK}+45 \mathrm{~kg} / \mathrm{ha} \mathrm{ZA} \\
\text { (dicor), yang diberikan pada } \\
\text { saat tanaman sebanyak } 8 \mathrm{kali} \\
\text { dengan interval waktu } 10 \\
\text { hari. }\end{array}$ \\
\hline 5 & $\begin{array}{l}\text { Pemeliharaan } \\
\text { - Penyiangan } \\
\text { - Pengendalian OPT }\end{array}$ & $\begin{array}{l}\text { Dilakukan penyiangan, tapi } \\
\text { tidak sempurna. } \\
\text { Pengendalian OPT dilakukan } \\
\text { dengan interrval dan dosis } \\
\text { pemberian tidak jelas, } \\
\text { dilakukan dengan } \\
\text { penyemprotan }\end{array}$ & $\begin{array}{l}\text { Dilakukan penyiangan } \\
\text { dengan sempurna } \\
\text { Pengendalian OPT delakukan } \\
\text { dengan metode PHT }\end{array}$ \\
\hline
\end{tabular}

Sumber : Analisis data peimer Penelitian (diolah), 2016.

Dari Tabel 11 dapat disimpulkan bahwa petani cabai merah belum melakukan pengolahan lahan dengan sempurna. Penggunaan pupuk yang tidak tepat dosis dan pupuk yang diberikan tidak beraturan. Penanganan OPT yang belum optimal juga menjadi kendala untuk mengurangi hama.

\section{KESIMPULAN DAN SARAN}

Berdasarkan hasil penelitian dan pembahasan, maka dapat diambil kesimpulan sebagai berikut

Analisis Daya Saing Beberapa Tanaman Sayuran Di Lahan Sawah Di Kecamatan Peukan Bada Kabupaten Aceh Besar (Tiara Sucia, Romano, Irwan A Kadir) Jurnal Ilmiah Mahasiswa Pertanian Unsyiah, Vol. 2, No. 3, Agustus 2017: 156-171 
1. Berdasarkan hasil analisis pendapatan, efisiensi usahatani (R/C ratio) titik impas produksi, titik impas harga dan analisis keunggulan kompetitif dihasilkan bahwa bawang merah, cabai merah dan cabai rawit secara ekonomis memiliki daya saing.

2. Fakto-faktor pendukung sarana produksi usahatani bawang merah di Kecamatan Peukan Bada bukan hanya bibit unggul. Hasil perbandingan kondisi di lapangan penelitian dan Rekomendasi BPTP Aceh, pupuk dan teknik budidaya juga berpengaruh pada produksi usahatani bawang merah.

\section{DAFTAR PUSTAKA}

Arikunto,S. 2002. Prosedur Penelitian, Suatu Pendekatan dan Praktek. PT.Rineka Cipta. Jakarta.

Baharsyah. (1995). Pengantar Ekonomi Sumber Daya Manusia. Lembaga Fakultas Ekonomi Universitas Indonesia .Jakarta.

Khoirunnisa, Atika., Dwi Haryono, Adia Nugraha. 2013. Analisis Pendapatan dan Pengambilan Keputusan dalam Menentukan Tanaman Sayuran Unggulan di Kecamatan Gisting Kabupaten Tanggamus. JIIA, Volume 1 No. 2, april 2013. Program Studi Agribisnis, Fakultas Pertanian, Universitas Lampung. Lampung.

Krisdiana, Ruly. 2011. Daya Saing dan Faktor Determinan Usahatani Kedelai di Lahan Sawah. Balai penelitian Tanaman dan Kacang-Kacangan dan Umbi-Umbian. Malang

Nazir. 2003. Metode Penelitian. Ghalia Indonesia. Jakarta.

Putra, I Gede Setiawan Adi., Pang S. Asngari, dan Prabowo Tjitropranoto. 2006. Dinamika Petani Beragribisnis Salak. Jurnal Penyuluh ISSN: 18582664. Bali.

Ramli, Rachmadi dan Dewa K S. Swastika. 2005. Analisi Keunggulan Kompetitif Beberapa Tanaman Palawija di Lahan Pasang Surut Kalimantan Tengah. Jurnal Vol 8, No 12005 . Jurnal pengkajian dan Pengembangan Teknologi Pertanian, Badan Litbang Pertanian, Kementrian Pertanian-Republik Indonesia.

Soekartawi.1996.Prinsip Dasar Ekonomi Pertanian: Teori dan Implikasinya. Rajawali Press. Jakarta.

Syukur, Muhammad., Rahmi Yunianti dan Rahmansyah Dermawan. 2016.

Budidaya Cabai, Panen Setiap Hari. Penebar Swadaya. Jakarta.

Analisis Daya Saing Beberapa Tanaman Sayuran Di Lahan Sawah Di Kecamatan Peukan Bada Kabupaten Aceh Besar (Tiara Sucia, Romano, Irwan A Kadir) 